\title{
Capillary leak syndrome in COVID-19 and post COVID-19 vaccines
}

\author{
Luca Roncati ${ }^{1, *}$, Greta Gianotti ${ }^{1}$, Elisa Ambrogi ${ }^{1}$, Giovanna Attolini ${ }^{1}$ \\ ${ }^{1}$ Department of Surgery, Medicine, Dentistry and Morphological Sciences with interest in Transplantation, Oncology and Regenerative Medicine, University \\ of Modena and Reggio Emilia, 41124 Modena, Italy \\ *Correspondence: luca.roncati@unimore.it; roncati.luca@aou.mo.it; emailmedical@gmail.com (Luca Roncati)
}

DOI:10.31083/j.ejg04205126

This is an open access article under the CC BY 4.0 license (https://creativecommons.org/licenses/by/4.0/).

Submitted: 16 August 2021 Revised: 19 August 2021 Accepted: 23 August 2021 Published: 15 October 2021

Coronavirus Disease 2019 (COVID-19) is the most dramatic pandemic of the new millennium with repercussions also in the gynecological oncology field [1-3]. The cervical cancer screening and the management of gynecological tumors have been negatively impacted by COVID-19, with many interventions delayed or postponed [4]. Once infected, oncological patients are in addition at a higher risk of developing a severe form of the disease, due to chemotherapy and immunocompromisation [5, 6]. To counteract all this, specific vaccines have been launched in record time under emergency use authorization or conditional marketing authorization [7]; however, very rare neurological (GuillainBarré syndrome) and thrombotic events after Vaxzevria ${ }^{\circledR}$ (formerly COVID-19 Vaccine AstraZeneca) or COVID-19 Vaccine Janssen have caused a stir in the scientific community and public opinion [7]. If Guillain-Barré syndrome is a known possible adverse reaction to vaccination, in which the immune system mistakenly attacks and damages peripheral nerves' myelin [8-10], for thrombotic events the matter is quite different. In fact, these severe, even fatal, thrombotic events have been only recently traced back to autoimmune thrombotic thrombocytopenia mediated by plateletactivating antibodies against platelet factor 4, which clinically mimics autoimmune heparin-induced thrombocytopenia [11-13]. Therefore, the European Medicines Agency (EMA) has updated the product information of both the vaccines in the midst of vaccination campaign, as follows:

"thrombosis with thrombocytopenia syndrome, in some cases accompanied by bleeding, has been observed very rarely following vaccination with Vaxzevria ${ }^{\circledR}$. This includes severe cases presenting as venous thrombosis, including unusual sites such as cerebral venous sinus thrombosis, splanchnic vein thrombosis, as well as arterial thrombosis, concomitant with thrombocytopenia. Some cases had a fatal outcome. The majority of these cases occurred within the first three weeks following vaccination and occurred mostly in women under 60 years of age" and "a combination of thrombosis and thrombocytopenia, in some cases accompanied by bleeding, has been observed very rarely following vaccination with COVID-19 Vaccine Janssen. This includes severe cases of venous thrombosis at unusual sites such as cerebral venous sinus thrombosis, splanchnic vein thrombosis as well as arterial thrombosis concomitant with thrombocytopenia. Fatal outcome has been reported. These cases occurred within the first three weeks following vaccination, and mostly in women under 60 years of age" $[14,15]$.

More recently, EMA's safety committee has reviewed six cases and three cases of Capillary Leak Syndrome (CLS) in people who had received Vaxzevria ${ }^{\circledR}$ and COVID-19 Vaccine Janssen, respectively. Most of the cases occurred in women and within four days from vaccination; four of those affected had a CLS history and three of them subsequently died $[16,17]$. But what exactly is CLS? It represents a serious and temporary (1-3 days) capillary disfunction typically of the middle-aged adults characterized by hyperpermeability, maybe related to proinflammatory mediators, in which blood plasma escapes from the circulatory system into interstitial compartment, surrounding tissues or body cavities, up to $70 \%$ of total plasma volume $[18,19]$. The extravasation in the extremities is so massive to cause generalized edema with rapid weight gain, hypotension, hemoconcentration, hypoalbuminemia, and compartment syndromes, accompanied by lipothymia or syncope and flu-like symptoms (Fig. 1); preserved consciousness, despite severe attack, is an additional and intriguing clinical manifestation often reported during episodes at hospital admission [20]. Death may occur for hypovolemic shock, arrhythmia, multiple organ failure, recovery-phase pulmonary edema, or ischemia-reperfusion injuries [20]. Moreover, in approximately four fifths of cases, a paraproteinemia is found as the expression of an underlying monoclonal gammopathy of unknown significance [18-20]. There is a primary form of CLS, also called Clarkson's disease (from the physicians Bayard D. Clarkson who first described it in 1960) [21], and a secondary form, due to ovarian hyperstimulation, differentiation syndrome, drugs (e.g., gemcitabine and tagraxofusp), sepsis, systemic inflammatory response syndrome, autoimmune diseases, hemophagocytic lymphohistiocytosis, engraftment syndrome, anaphy- 


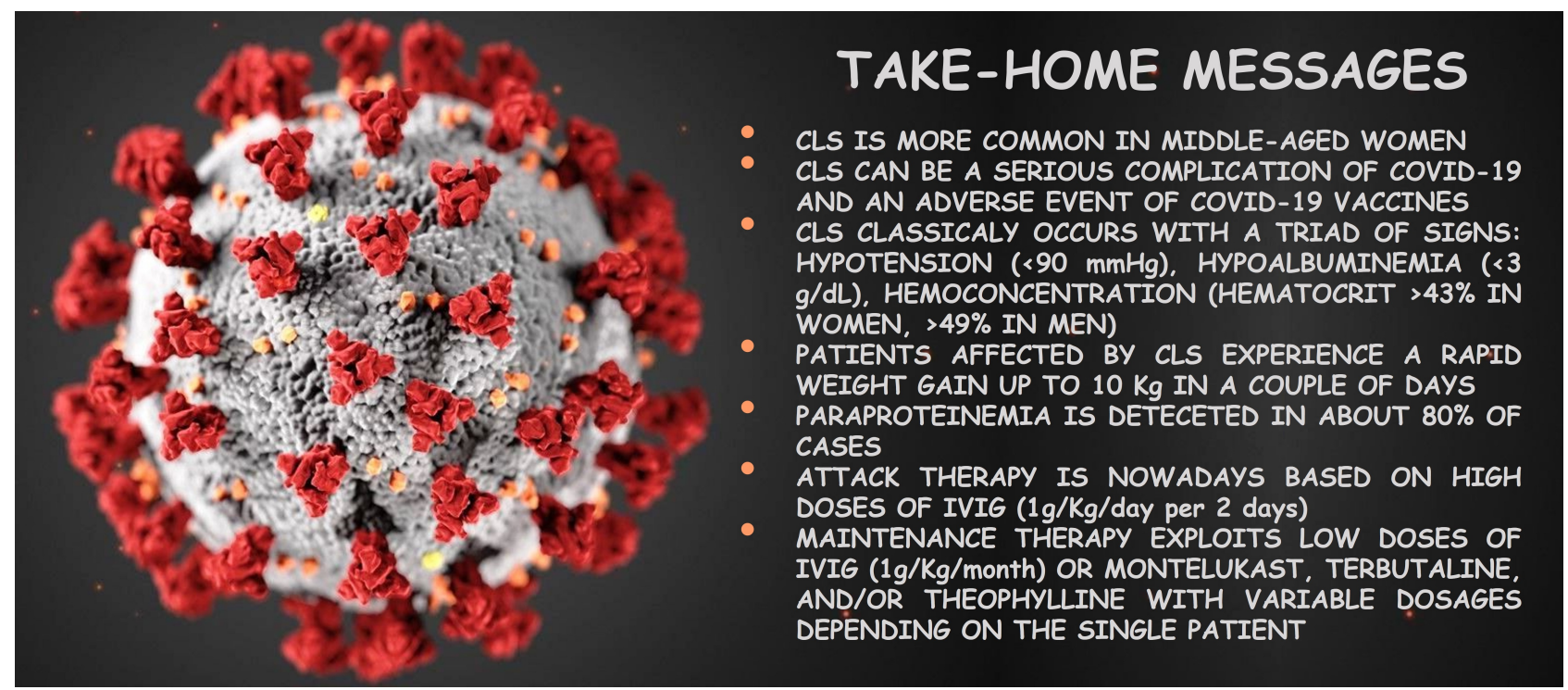

Fig. 1. Take-home messages of CLS in COVID-19 and post COVID-19 vaccines [the 3D illustration of SARS-CoV-2 has been drawn by Alissa Eckert, MS, and Dan Higgins, MAM, at the Centers for Disease Control and Prevention (CDC) of Atlanta, Georgia, USA, placed in the public domain and thus free of any copyright restrictions].

laxis, systemic mastocytosis, toxicity, snakebite, ricin poisoning, viral hemorrhagic fevers and other infections [18-20]. Surprisingly, COVID-19 has been reported by various authors among the infectious diseases able to unleash CLS [2228]. Worldwide, COVID-19 vaccination campaign is carried out through modRNA-based or viral vector-based vaccines [29]. The latters contain genetically modified adenoviruses by recombinant DNA technology encoding the spike glycoprotein of the Severe Acute Respiratory Syndrome Coronavirus 2 (SARS-CoV-2) $[14,15]$, the etiological agent of COVID-19 [30, 31]; it is therefore reasonable to assume that a viral vector loaded with the spike SARS-CoV-2 DNA can elicit CLS in rare, predisposed individuals. In fact, the product information of Vaxzevria ${ }^{\circledR}$ and COVID-19 Vaccine Janssen has been respectively updated by EMA, as follows:

"very rare cases of CLS have been reported in the first days after vaccination with Vaxzevria ${ }^{\circledR}$. A history of CLS was apparent in some of the cases. Fatal outcome has been reported. ... Individuals with a known history of CLS should not be vaccinated with this vaccine" and "very rare cases of CLS have been reported in the first days after vaccination with COVID19 Vaccine Janssen, in some cases with a fatal outcome. A history of CLS has been reported. ... Individuals with a known history of CLS should not be vaccinated with this vaccine" $[14,15]$.

The same update procedure has not been applied to Comirnaty ${ }^{\circledR}$ (formerly COVID-19 Vaccine Pfizer/BioNTech) and Spikevax ${ }^{\circledR}$ (previously COVID19 Vaccine Moderna), even though Matheny and colleagues have described two cases of CLS after these modRNAbased vaccines [32], which anyway remain of choice for patients suffering from gynecological malignancies. Today, a prompt recognition of post-vaccinal CLS is crucial, since it responds well to an early administration of IntraVenous ImmunoGlobulins (IVIG) at high doses $(1 \mathrm{~g} / \mathrm{Kg} /$ day per 2 days), to be associated with supportive therapy [33, 34].

\section{Author contributions}

LR conceived, designed, and supervised the study, interpreted the data, prepared the figure with the related legend, and wrote the manuscript; GG analyzed the data; EA and GA performed the literature search. All authors read and approved the final version of the manuscript.

\section{Ethics approval and consent to participate}

Not applicable.

\section{Acknowledgment}

Not applicable.

\section{Funding}

This research received no external funding.

\section{Conflict of interest}

The authors declare no conflict of interest. LR is the Associate Editor of this Journal; given his role as Associate Editor, he was not involved in the peer-review of this article and had no access to information regarding its peer-review.

\section{References}

[1] Tsibulak I, Reiser E, Bogner G, Petru E, Hell-Teutsch J, Reinthaller A, et al. Decrease in gynecological cancer diagnoses during the COVID-19 pandemic: an Austrian perspective. International Journal of Gynecologic Cancer. 2020; 30: 1667-1671.

[2] Roncati L, Gianotti G, Ambrogi E, Attolini G. COVID-19 in pregnancy. Clinical and Experimental Obstetrics \& Gynecology. 2021; 48: 778 . 
[3] Roncati L, Ligabue G, Nasillo V, Lusenti B, Gennari W, Fabbiani $\mathrm{L}$, et al. A proof of evidence supporting abnormal immunothrombosis in severe COVID-19: naked megakaryocyte nuclei increase in the bone marrow and lungs of critically ill patients. Platelets. 2020; 31: 1085-1089.

[4] Gourd E. COVID-19 pandemic causes cervical cancer screening crisis. The Lancet Oncology. 2021; 22: 1060.

[5] Dai M, Liu D, Liu M, Zhou F, Li G, Chen Z, et al. Patients with cancer appear more vulnerable to SARS-CoV-2: a multicenter study during the COVID-19 outbreak. Cancer Discovery. 2020; 10: 783791.

[6] Roncati L, Nasillo V, Lusenti B, Riva G. Signals of Th2 immune response from COVID-19 patients requiring intensive care. Annals of Hematology. 2020; 99: 1419-1420.

[7] Roncati L, Roncati M. Emergency use authorization (EUA), conditional marketing authorization (CMA), and the precautionary principle at the time of COVID-19 pandemic. Journal of Public Health Policy. 2021. (in press)

[8] McKean N, Chircop C. Guillain-Barré syndrome after COVID-19 vaccination. BMJ Case Reports. 2021; 14: e244125.

[9] Hasan T, Khan M, Khan F, Hamza G. Case of Guillain-Barré syndrome following COVID-19 vaccine. BMJ Case Reports. 2021; 14 : e243629.

[10] Patel SU, Khurram R, Lakhani A, Quirk B. Guillain-Barre syndrome following the first dose of the chimpanzee adenovirusvectored COVID-19 vaccine, ChAdOx1. BMJ Case Reports. 2021; 14: e242956.

[11] Scully M, Singh D, Lown R, Poles A, Solomon T, Levi M, et al. Pathologic Antibodies to Platelet Factor 4 after ChAdOx1 nCoV19 Vaccination. New England Journal of Medicine. 2021; 384: 2202-2211.

[12] Schultz NH, Sørvoll IH, Michelsen AE, Munthe LA, LundJohansen F, Ahlen MT, et al. Thrombosis and Thrombocytopenia after ChAdOx1 nCoV-19 Vaccination. New England Journal of Medicine. 2021; 384: 2124-2130.

[13] Greinacher A, Thiele T, Warkentin TE, Weisser K, Kyrle PA, Eichinger S. Thrombotic Thrombocytopenia after ChAdOx1 nCov-19 Vaccination. New England Journal of Medicine. 2021; 384: 2092-2101.

[14] European Medicines Agency. Vaxzevria (previously COVID-19 Vaccine AstraZeneca). 2021. Available at: https://www.ema.europa.eu/en/documents/product-infor mation/vaxzevria-previously-covid-19-vaccine-astrazeneca-epa r-product-information_en.pdf (Accessed: 19 July 2021).

[15] European Medicines Agency. COVID-19 Vaccine Janssen. 2021. Available at: https://www.ema.europa.eu/en/documents/produ ct-information/covid-19-vaccine-janssen-epar-product-infor mation_en.pdf (Accessed: 4 August 2021).

[16] European Medicines Agency. Vaxzevria: EMA advises against use in people with history of capillary leak syndrome. 2021. Available at: https://www.ema.europa.eu/en/news/vaxzevria-ema-a dvises-against-use-people-history-capillary-leak-syndrome (Accessed: 11 June 2021).

[17] European Medicines Agency. EMA advises against use of COVID-19 Vaccine Janssen in people with history of capillary leak syndrome. 2021. Available at: https: //www.ema.europa.eu/en/news/ema-advises-against-use-cov id-19-vaccine-janssen-people-history-capillary-leak-syndrome (Accessed: 9 July 2021).

[18] Siddall E, Khatri M, Radhakrishnan J. Capillary leak syndrome: etiologies, pathophysiology, and management. Kidney International. 2017; 92: 37-46.
[19] Kapoor P, Greipp PT, Schaefer EW, Mandrekar SJ, Kamal AH, Gonzalez-Paz NC, et al. Idiopathic systemic capillary leak syndrome (Clarkson's disease): the Mayo clinic experience. Mayo Clinic Proceedings. 2010; 85: 905-912.

[20] Pineton de Chambrun M, Luyt C, Beloncle F, Gousseff M, Mauhin W, Argaud L, et al. The Clinical Picture of Severe Systemic Capillary-Leak Syndrome Episodes Requiring ICU Admission. Critical Care Medicine. 2017; 45: 1216-1223.

[21] Clarkson B, Thompson D, Horwith M, Luckey EH. Cyclical edema and shock due to increased capillary permeability. The American Journal of Medicine. 1960; 29: 193-216.

[22] Pineton de Chambrun M, Cohen-Aubart F, Donker DW, Cariou $\mathrm{P}$, Luyt C, Combes A, et al. SARS-CoV-2 Induces Acute and Refractory Relapse of Systemic Capillary Leak Syndrome (Clarkson's Disease). The American Journal of Medicine. 2020; 133: e663e664.

[23] Cheung PC, Eisch AR, Maleque N, Polly DM, Auld SC, Druey KM. Fatal exacerbations of systemic capillary leak syndrome complicating coronavirus disease. Emerging Infectious Diseases. 2021. (in press)

[24] Bahloul M, Ketata W, Lahyeni D, Mayoufi H, Kotti A, Smaoui F, et al. Pulmonary capillary leak syndrome following COVID-19 virus infection. Journal of Medical Virology. 2021; 93: 94-96.

[25] Case R, Ramaniuk A, Martin P, Simpson PJ, Harden C, Ataya A. Systemic Capillary Leak Syndrome Secondary to Coronavirus Disease 2019. Chest. 2020; 158: e267-e268.

[26] Lacout C, Rogez J, Orvain C, Nicot C, Rony L, Julien H, et al. A new diagnosis of systemic capillary leak syndrome in a patient with COVID-19. Rheumatology. 2021; 60: e19-e20.

[27] Wu MA, Fossali T, Pandolfi L, Carsana L, Ottolina D, Frangipane $\mathrm{V}$, et al. Hypoalbuminemia in COVID-19: assessing the hypothesis for underlying pulmonary capillary leakage. Journal of Internal Medicine. 2021; 289: 861-872.

[28] Beber A, Dellai F, Abdel Jaber M, Peterlana D, Brunori G, Maino A. Systemic capillary leak syndrome triggered by SARS-CoV2 infection: case report and systematic review. Scandinavian Journal of Rheumatology. 2021. (in press)

[29] Roncati L, Corsi L. Nucleoside-modified messenger RNA COVID-19 vaccine platform. Journal of Medical Virology. 2021; 93: 4054-4057.

[30] Roncati L, Gallo G, Manenti A, Palmieri B. Renin-angiotensin system: the unexpected flaw inside the human immune system revealed by SARS-CoV-2. Medical Hypotheses. 2020; 140: 109686.

[31] Roncati L, Palmieri B. What about the original antigenic sin of the humans versus SARS-CoV-2? Medical Hypotheses. 2020; 142: 109824.

[32] Matheny M, Maleque N, Channell N, Eisch AR, Auld SC, Banerji $A$, et al. Severe exacerbations of systemic capillary leak syndrome after COVID-19 vaccination: a case series. Annals of Internal Medicine. 2021. (in press)

[33] Lambert M, Launay D, Hachulla E, Morell-Dubois S, Soland V, Queyrel V, et al. High-dose intravenous immunoglobulins dramatically reverse systemic capillary leak syndrome. Critical Care Medicine. 2008; 36: 2184-2187.

[34] Xie Z, Chan EC, Long LM, Nelson C, Druey KM. High-dose Intravenous Immunoglobulin Therapy for Systemic Capillary Leak Syndrome (Clarkson Disease). The American Journal of Medicine. 2015; 128: 91-95. 